01.4;05.3;06.1

\title{
Особенности фазовых превращений растворов полимеров в деформируемых пористых матрицах
}

\author{
(C) А.В. Шишулин, В.Б. Федосеев \\ Институт металлоорганической химии им. Г.А. Разуваева РАН, Нижний Новгород, Россия \\ E-mail: chichouline_alex@live.ru
}

Поступило в Редакцию 5 апреля 2019г.

В окончательной редакции 11 апреля 2019г.

Принято к публикации 11 апреля 2019г.

\begin{abstract}
Методами равновесной химической термодинамики смоделированы закономерности влияния геометрических факторов (формы и объема поры) на фазовые равновесия в расслаивающихся растворах в пористой матрице. На примере системы полибутадиен-полистирол, расслаивающейся в жидком состоянии, показано, что деформация матрицы, задающая геометрические характеристики пор, позволяет управлять взаимными растворимостями компонентов, объемами и термодинамической устойчивостью сосуществующих при равновесии фаз. Значительные деформации матрицы приводят к подавлению расслаивания в порах, когда устойчивыми становятся любые составы растворов (вплоть до эквимолярного).
\end{abstract}

Ключевые слова: пористые материалы, фазовые превращения, core-shell, деформация, расслаивание.

DOI: 10.21883/PJTF.2019.14.48014.17826

Микро- и наноструктурные композиционные материалы на основе пористых матриц с включениями жидких $[1,2]$ или твердых $[3,4]$ растворов имеют широкий спектр технологических приложений. Специфические свойства таких композитов в значительной степени обусловлены отличием свойств материалов в микро- и наноструктурах (например, в микро- и нанопорах [1,2], наночастицах [3] и зернах поликристаллического материала [4]) от присущих материалам в макроскопическом состоянии. В частности, термодинамические параметры (температуры, давления и т.д.) фазовых переходов [3,5], равновесный фазовый состав в микроструктурах $[1,3,5]$, набор возможных фаз [3,5], их термодинамическая стабильность, а также весь комплекс связанных с фазовым составом свойств могут существенно отличаться от аналогичных характеристик для макросистем. В настоящей работе в рамках термодинамического подхода на примере жидкого бинарного расслаивающегося полимерного раствора в деформируемой пористой матрице показаны закономерности влияния объема и формы поры (задаваемых степенью деформации матрицы) на фазовые равновесия и фазовые переходы во внутрипоровом растворе.

Объектами моделирования являются включения эквимолярного состава жидкого расслаивающегося раствора полибутадиена (PBD) и полистирола (PS) в порах деформируемой матрицы при температуре $T=300 \mathrm{~K}$. Предполагается, что при расслаивании в поре образуется единичное сферическое включение жидкого раствора, окруженное жидким слоем другого состава (core-shellструктура). Поры в недеформированной матрице имеют сферическую форму. Положим, что при деформации они приобретают форму эллипсоидов (деформация одноосного растяжения/сжатия); сжимаемость жидкости в поре, согласно [2], не учитывается. Для описания формы поры используем безразмерный коэффициент формы поры $k$, численно равный отношению площади внутренней поверхности эллиптической поры в деформированной матрице $A$ к площади внутренней поверхности исходной сферической поры $A_{0}: k=A / A_{0}$ (более детальное изложение данного формализма и обзор различных подходов, включая фрактальные, для параметрического описания геометрических характеристик структуры даны в $[1,3,5-7]$.

Равновесный состав сосуществующих фаз определяется минимизацией функции Гиббса с учетом энергетического вклада всех границ раздела, при этом объем и коэффициент формы поры, задающие площадь внешней межфазной границы, являются параметрами расчета (основные уравнения модели расслаивания жидких и твердых растворов в системах ограниченного объема подробно приведены в $[1,3,5])$. Функция Гиббса рассматриваемой системы для каждой из фаз построена в рамках модели Флори-Хаггинса (см. выражения (5), (6) в [8]) с коэффициентами, полученными на основе систематизированных экспериментальных данных (табл. 4 в [8]). Поверхностные натяжения жидких растворов на внешней (shell) границе описываются в линейном приближении $[1,3]$, температурные зависимости поверхностных натяжений чистых PBD и PS получены в [9]. Поскольку, как показано в [10], величина вклада дисперсионных взаимодействий в поверхностное натяжение обоих компонентов превышает 80\%, энергия внутренней (core-shell) границы оценивалась в рамках модели Фоукса (см. выражение (65) в [9]).

Функция Гиббса для core-shell-структуры обладает двумя минимумами, различающимися тем, какой из сосуществующих растворов находится в положении shell-фазы. В системе малого объема равновесные со- 

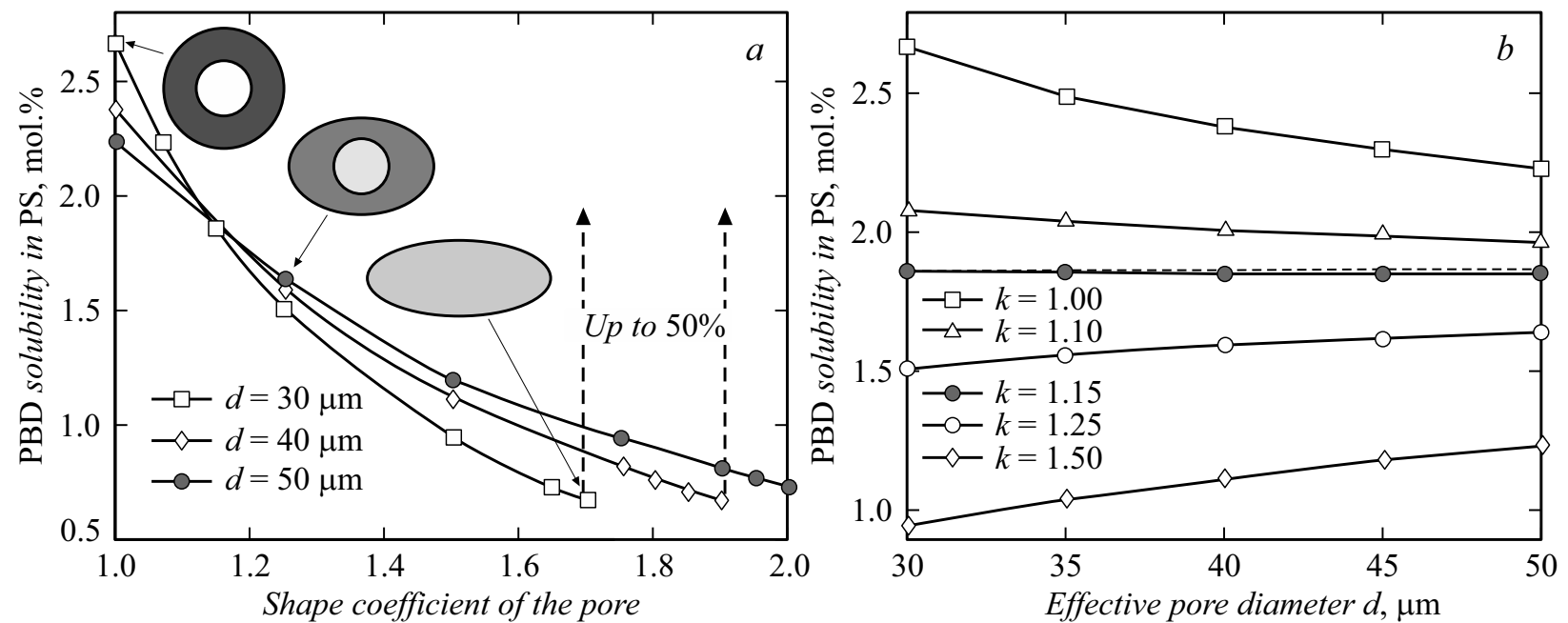

Зависимость растворимости PBD в PS от размера и коэффициента формы поры $k$ для состояния, где shell-фаза образована раствором на основе PS. По оси абсцисс отложены: на части $a-$ коэффициент формы поры, на части $b-$ величина эффективного диаметра поры $d$ (диаметра сферической поры равного объема). Штриховой линией на части $b$ показана растворимость в системе макроскопического размера [8].

ставы и объемы сосуществующих фаз в этих двух состояниях различаются между собой $[1,3,5]$ и зависят от объема и формы поры. При этом состояние с раствором на основе PBD в shell-положении, имеющее более высокую поверхностную энергию, является метастабильным, и его образование менее вероятно. Далее рассматривается случай, когда shell-фаза образована раствором на основе PS. Полученные на основе термодинамических расчетов зависимости взаимных растворимостей компонентов от размера и формы поры представлены на рисунке.

Как показано на рисунке, $a$, растворимость PBD в PS в порах любого объема монотонно уменьшается при деформации матрицы. Например, в сферической поре диаметром $40 \mu \mathrm{m}$ растворимость полистирола составляет $\sim 2.38 \mathrm{~mol} . \%$, а в поре того же объема с $k=1.50-$ $\sim 1.12$ mol.\%. При этом реакция растворимости PBD в PS на изменение объема поры различна для пор разной формы (см. рисунок, $b$ ): в интервале $1.00<k<1.15$ с уменьшением объема поры растворимость растет, в области $k>1.15$ уменьшается. Линия, соответствующая $k=1.15$, служит своего рода „сепаратрисой“, разделяющей области роста и уменьшения: при данном значении $k$ растворимость практически не зависит от размера поры и близка к макроскопическому значению (штриховая линия на рисунке, $b$ ). При критических степенях деформации (убывающих при уменьшении объема поры) расслаивание подавляется вовсе (вертикальные штриховые линии на рисунке, $a$ ): образование внутренней межфазной границы является термодинамически невыгодным, и полимерная смесь в поре существует в гомогенном эквимолярном (50\% PBD) состоянии.

Отклонения равновесного фазового состава системы от макроскопических значений и подавление расслаивания являются следствием понижения свободной энергии системы, что реализуется посредством трех различных механизмов. При малых $k(1.00<k<1.15)$, когда форма поры близка к сферической, уменьшение объема вызывает преимущественный перенос в shell-фазу компонента с бо́льшим мольным объемом (PBD), что приводит к уменьшению площади внутренней межфазной границы. В результате растет растворимость PBD в PS и падает объемная доля core-фазы (при этом энергетический „выигрыш“, связанный с уменьшением энергии границ раздела, превышает „проигрыш“, связанный с формированием пересыщенных по сравнению с макроскопическими значениями [8] растворов). В порах несферической конфигурации при $k>1.15$, когда площадь внешней межфазной границы велика, с уменьшением объема поры происходит преимущественное обогащение shell-фазы компонентом с меньшим поверхностным натяжением (PS), приводящее к уменьшению энергетического вклада внешней границы раздела; при этом растворимость PBD в PS падает (см. рисунок, $b$ ) (деформация матрицы при заданном объеме поры также активирует данный механизм, см. рисунок, $a$ ). При $k=1.15$ два указанных конкурирующих механизма „компенсируют“ друг друга, и растворимость PBD слабо чувствительна к уменьшению объема поры и почти не отличается от макроскопического значения. При малых размерах пор (в сферических порах диаметром менее $15 \mu \mathrm{m}$ ), а также при высоких $k$ (например, $k>1.7$ при $d=30 \mu \mathrm{m}$, см. рисунок, $a$ ) расслаивание „Подавляется“.

Выполненные термодинамические оценки демонстрируют возможность создания систем, где число, составы и термодинамическая устойчивость фаз, а также весь комплекс свойств, связанных с равновесным фазовым составом $[2,4]$, могут быть заданы и управляться путем простых внешних воздействий (например, деформацией пористой матрицы). Возможность управляемого пере- 
хода между различными термодинамически устойчивыми состояниями системы делает полученные закономерности актуальными при создании и моделировании адаптивных мультистабильных систем, например мемристивных устройств [11] и соответствующих элементов нейронных сетей [12].

\section{Финансирование работы}

Работа выполнена в соответствии с государственным заданием ИМХ РАН, а также при поддержке Российского фонда фундаментальных исследований (проекты 18-08-01356-а и 18-43-520034-р_поволжье_а).

\section{Конфликт интересов}

Авторы заявляют, что у них нет конфликта интересов.

\section{Список литературы}

[1] Shishulin A.V., Fedoseev V.B. // J. Mol. Liq. 2019. V. 278. P. 363-367.

[2] Брагов А.М., Игумнов Л.А., Константинов А.Ю., Ломунов А.К., Антонов Ф.К., Моссаковский П.А. // Письма в ЖТФ. 2014. Т. 40. В. 20. С. 82-87.

[3] Шишулин А.В., Федосеев В.Б., Шишулина А.В. // ЖТФ. 2019. T. 89. B. 4. C. $556-561$.

[4] Барышников С.В., Милинский А.Ю., Чарная Е.В., Егорова И.В. // ФТТ. 2019. Т. 61. В. 2. С. 273-277.

[5] Федосеев В.Б., Шишулин А.В. // ФТТ. 2018. Т. 60. В. 7. C. $1382-1388$.

[6] Магомедов М.Н. // Письма в ЖТФ. 2016. Т. 42. В. 14. C. 94-102.

[7] Магомедов М.Н. // ЖТФ. 2016. Т. 86. В. 5. С. 84-91.

[8] Li Y.C., Wang C.P., Liu X.J. // CALPHAD. 2009. V. 33. P. 415-419.

[9] $W u$ S. // J. Macromol. Sci. C. 1974. V. 10. P. 1-73.

[10] Jia L., Shi B. // J. Macromol. Sci. B. 2011. V. 50. P. 1042 1046.

[11] Белов А.И., Михайлов А.Н., Королев Д.С., Сергеев В.А., Антонов И.Н., Горшков О.Н., Тетельбаум Д.И. // Письма в ЖТФ. 2016. Т. 42. В. 10. С. 17-24.

[12] Герасимова С.А., Михайлов А.Н., Белов А.И., Королев Д.С., Горшков О.Н., Казанцев В.Б. // ЖТФ. 2017. Т. 87. B. 8. C. $1248-1254$. 